\title{
Social work with older adults in primary health - is it time to move our focus?
}

\author{
Sue Foster and Liz Beddoe
}

Sue Foster is a social work supervisor and a research fellow with the Freemasons' Dept of Geriatric Medicine at the University of Auckland. Liz Beddoe is an Associate Professor of Social Work in the School of Counselling, Human Services and Social Work at the University of Auckland.

\section{Abstract}

Social work has made a significant contribution to the health care of older people for the last 60 years. At any one time, older people make up a significant number of our inpatient population in public hospitals. Social workers have not only had an integral part to play in discharge planning of this vulnerable population but also have played an important advocacy and support role with the patient and their families. Indeed, social work is traditionally the discipline that links the medical world to the patient's world in the community.

Recent data indicates the average length of stay (ALOS) in public hospitals is continuing to decline. Between 2001 and 2010, total ALOS decreased from 4.4 days to 4.1 days and in medical wards from 3.9 days to 3.5 days (Ministry of Health, 2011). (MOH).Ward managers have traditionally relied on social workers to provide safe discharges, particularly for older people who are vulnerable, but the pressure to concentrate on this service has increased as the pressure to manage very high bed occupancy also grows. Anecdotal evidence indicates that some social workers have been directed to attend to discharge planning only and any other issues that are identified are to be referred to their community colleagues. This demanding environment poses challenges for social work and raises the question whether more effective social work intervention for older people could be achieved in the community. Where should social workers concentrate their efforts in order to have the most effective outcomes? Would health social work be more effective if placed in the primary care sector? This article examines the skill base of health social workers in relation to working with older people, and argues that a move into primary care would result in a more effective use of our skill base which is after all centred in family work.

\section{Introduction: Social work in healthcare}

Social work in health settings has been in existence for more than 100 years (Auslander, 2001). In New Zealand, social work in health settings emerged from nursing, with first published references made to social work in health care found in 1939 (Beddoe \& Deeney, 2012). For much of this time social workers have been based in hospitals where their main role has been to provide a bio-psychosocial assessment and intervention service in the midst of a medical setting as well as providing emotional support to patients and their families as they 
traverse the inpatient pathway (Schofield, 2001). Above all the aim of the social work role has been to preserve focus on the unique identity of the patient in the face of increasingly pressurised medical care. Historically, health institutions have not always been a comfortable place for social work (Bywaters, 1986), and indeed the role for social work has appeared to diminish over recent years for a number of reasons. Social work in health care has often staked its claim to territory in the health system on its expertise in the 'psychosocial' aspects of illness, based on a persistent view that other health professions limited their focus on physical factors and treatment of service users in health systems (Beddoe, 2011). As such the knowledge base for health practice has often reflected a focus on psychological and social functioning of those encountering the disruption of illness in personal and family life. The special contribution made by social work in multidisciplinary teams is not always wellunderstood, and literature reports this problem as a persistent challenge for the profession (Opie \& Munford, 1995). Narrow expectations of social workers may produce less than optimal intervention. As Weld (2009) asserts:

A narrow task-centred approach to social work and role confusion can impact on job satisfaction and result in poor social work staff retention. Limited assessments also do not ascertain the wellbeing, coping and safety of the people to whom we have a duty of care, nor highlight wider social disparities or community issues (p. 26).

In addition, over time, the nursing and medical professions have moved to focus on training graduates in interpersonal and communication skills as core clinical competencies, as well as developing skills in understanding the psychosocial implications of illness. Consequently the concept of client-centred care is no longer primarily the domain of social work and this has created a situation where many social workers in health care feel that they are competing for professional ground. Barnes and Hugman (2002) have noted that one of the consequences of change in health and social care is that there is a:

... blurring of boundaries with other professions ... This leads to a renewed concern with questions of what is unique to social work and what is shared territory, and what are the implications for service delivery, arising from a reconsideration of boundaries (Barnes \& Hugman, 2002, p. 286).

Social workers may feel less able to soundly articulate their point of difference and feel that they are in competition with their medical and nursing colleagues. In a recent study looking at the professional identity of health social workers in New Zealand, Beddoe (2011), found that health social workers felt a lack of status in comparison to doctors and nurses, and in fact often used 'battle metaphors to describe their venturing into the medical world' (p.8). This concern that we measure and articulate our contribution clearly is intensified in recessionary times (Briggs \& Colhoun, 1990; Phillips, 1999). The fight for status and visibility is one which appears to dog social work as a profession within hospitals. These are real tensions but they can also distract and consume energy that could be directed into working collaboratively.

Alongside these strains, the creation of the Needs Assessment and Service Coordination (NASC) role through the Health and Disability Act of 1993 has in effect led to a transfer of a primarily social work role to other allied health professionals. The purpose of the Health and Disability Act was to provide a comprehensive assessment and service coordination service that were separate from each other, to people with disabilities in a way that gave 
disabled people more voice in the assessment process and also in negotiation for the services they required $(\mathrm{MOH}, 2011)$. For older people this new role was to form the gateway to provision of support services in the community as well as the first step leading to an assessment for residential care. This role was opened to more health professionals than social workers, including occupational therapists, nurses and physiotherapists among others, and ultimately the effect has been to dramatically reduce the presence of the social work role in the community, as most of the social workers at the time were redeployed into the NASC role. Earlier research by one of the authors (Foster, 2003) found that in the process of implementing this Act in the Auckland Central area in 1996, only two of the original complement of 15 community social workers remained - all the others had been transferred to the new role of Needs Assessor/Service Coordinator (NASC) role. Over time the NASC role has taken an increasingly essential part in discharge planning from acute care, and now many District Health Boards have attached their NASCs to hospital wards to facilitate this process. This has further eroded the social work role in the discharge planning process within hospitals. The focus for health social workers in the community has appeared to narrow to being involved with older people and their families around episodic crises, often following an admission to hospital, rather than working in areas of prevention with such issues as isolation, depression and anxiety, grief work and early identification of dementia, issues which often flag a visit to a GP.

\section{Background: The impact of demographic change}

As is the case in most OECD countries, New Zealand has an ageing population and it is envisaged that by $205025 \%$ of our population will be over the age of 65 years, and of those, $25 \%$ will be over the age of 85 years $(\mathrm{MOH}, 2002)$. Furthermore, due to improvements in life expectancy, we can expect further growth in Alzheimer's disease and in functional disability going hand-in-hand with the ageing of New Zealand's population (Booth, Miller \& Mor, 2007). Most of these older people will be based in the community as health policy has focused on the value of older people remaining in the community for as long as possible (Davey, 2006; Dwyer, Gray and Renwick, 2000). However, it is recognised that a high proportion of admissions to public hospitals are made up of older people, especially the very old (over 85). Many of these people are admitted with complex psychosocial issues that interact with medical problems that require more time for social work consideration than is currently afforded (Berkman, Gardner, Zodikoff \& Harootyan, 2005). Many of the issues that often present alongside medical problems on acute admission to hospital, such as dealing with increased frailty, depression and problems with alcohol, could be identified earlier in primary care settings and interventions provided for in the community in a more timely fashion (Rinfrette, 2009).

Primary care is commonly regarded as essential health care, with services made available in the community, ideally at an affordable cost and geared toward the well-being of all in the community. In New Zealand, social work in primary care is very much in the early stages of development. Elsewhere there is considerable interest in social work in primary care - see for example work being done by the Irish Association of Social Workers (IASW) (2011); and in Canada by the Canadian Association of Social Workers (n.d.). In Ireland, for example, policy suggests primary care social workers are 'uniquely placed to engage in community development aspects of prevention and health promotion with the communities in which they work, through appropriate training and support from our community work colleagues' (IASW, 2011 np). 
The World Health Organisation's (WHO) primary care strategy requires governments to 'promote maximum community and individual self-reliance and participation' in primary health care (WHO, 1978), and sees people as being 'at the centre' of primary care services. This conceptualisation of a patient and family-centred approach emphasises the importance of coordination and continuity as core functions (Smith \& Cumming, 2009). Accordingly, the New Zealand Primary Health Care strategy describes people as being 'a central part' of local primary care services (Smith \& Cumming, 2009). The strategy focuses on community participation, preventive services, and an environment that supports the 'self-care of individuals, whanau, family, communities and health providers achieving their potential, making decisions, maximising their choices and being part of the consultative process in relation to their health and wellbeing' (MOH, 2007a). The current government initiative of 'better, sooner, more convenient primary health care' (MOH, 2011) aims to see more personalised primary care that is closer to home, that takes the pressure off hospitals and improves population health. Changing trends internationally indicate the delivery of primary health care services have included multi-disciplinary teamwork and a move away from episodic reactive service delivery to more planned systematic service delivery (Smith \& Cumming, 2009). Services grounded in ideals of positive ageing also require attention to cultural needs and aspirations (Aldrich, 2010) and the rejection of ageism. These approaches incorporate a set of philosophies that the profession can clearly align with.

Chronic disease is a significant burden for older people, their caregivers and the health and social systems that support them. It is estimated that upwards of three-quarters of older people over 65 have at least one or more chronic diseases, and this number rises with age (Foote \& Stanners, 2002). This burden not only threatens physical activity but also increases psychological distress, social isolation and stress on caregivers, and problems with alcohol. The de-conditioning and depression which chronic diseases can bring can result in a vicious downward spiral of dependency. There is an increasing body of evidence that shows that structured interventions can have a major impact in improving the well-being of the older person, reducing stress on caregivers and rationalising and reducing demand on the health care system (Foote \& Stanners, 2002).

\section{The potential of the primary care context for social work with older adults}

Against this background of professional, policy and practice challenges the authors argue for a service model better designed to meet the needs of older adults and their caregivers.

Positioning social work in primary healthcare may increase awareness of the range of skills required in care of the elderly and reduce misunderstandings about the potential role and function of social work in health care. This requires action from social workers as there is danger that we reproduce the problems of the hospital- based multidisciplinary teams within primary care settings. Opie (1995) noted that social workers frequently undermined their position by use of vague, informal language to represent their activities. Working in primary care requires the ability to carry out and communicate about a wide range of complex social and emotional/psychotherapeutic interventions. Social work has at its heart values which promote relationship-based engagement with clients and their caregivers often contradicted by other policies and practices in the contemporary health care organisational context (Ruch, Turney \& Ward, 2010). Social work also requires courage to advocate for relationship-based work with elders, where policies may focus more on targets, costs, efficiencies and reduction 
of risk. As Cooper (2010) points out also the work of caring for the ageing, especially those with dementia, poses the need for 'psychic effort' to provide excellent care where there is a slow decline towards death and 'usually few tangible rewards for caring effort' (p.231).

At the time of writing, social work in primary health is in its infancy in New Zealand but has so much to offer. The potential for social work in primary care has been on the agenda before. Earlier work carried out in Christchurch (Craig, 1980; Botting \& Chetwynd, 1989) showed great potential for social work in primary care but with the cost cutting of the following few decades these hopes were not realised. Nuthall (1989) challenged the location of most health social workers in hospitals, who are only able to be reached by internal referrals and therefore out of reach of individuals and families needing services in their communities. Nuthall cited the Ottawa Charter for health promotion (1986) as stating that 'one of the essential components of creating a healthy society means moving resources from secondary care to primary health care' (1989, p.9). No recent research in New Zealand has been located but a study in the US confirmed the views of primary care professionals that time constraints, lack of awareness of community resources and providing more intensive psychosocial care (Keefe, Geron \& Enguidanos, 2009). Keefe et al found that both physicians and nurses recognised the contribution that could be made by a social worker. Barriers were perceived as location, funding and a voiced 'concern about potential time consumption of having a social worker in primary care' (p. 592). In spite of this latter potential problem, physicians and nurses in Keefe et al's study 'unanimously felt that the social workers must reside within the primary care setting on a full-time basis in order to provide sufficient support' (p.592).

There is some evidence that a move towards multi-disciplinary team work as a model of care for primary care patients is also gaining traction, as will be described below. It is increasingly recognised that for people with chronic health care needs, a single multi-skilled worker cannot provide all the support needs (Pack, 2008). For older people this is particularly so. For example, an older person may require highly skilled rehabilitation and have a nursing need such as a leg ulcer. Home-based or primary care services are generally very task oriented, with pressure for this type of activity to be done as quickly as possible - so while other professionals may have received wider training in psychosocial care, they are often frustrated by time commitments forcing them to focus on core activity. Also, general practitioners and practice nurses do not generally visit patients at home while a social worker would. Increasingly, older people are requiring help from an organisation that is able to respond to complex need. There may also be a need for adaptations in the home, or financial and housing advice. Health social work has critical skills in advocacy and care coordination, as well as an understanding of a wide range of medical diagnoses and their social implications. These are particularly valuable to the care of people with chronic illnesses, who often have multiple people and agencies in their lives. Older people, especially those who live alone and who do not have family support, often value the contribution of a social worker to come to terms with the changes in their health and also to help coordinate care. Social workers can also help with the transition from the community to hospital care, providing critical support and continuity for patients in their journey through an acute episode.

The current policy in New Zealand and elsewhere to encourage older people to age at home, rather than in institutional care, has had unintentional negative consequences for family members who care for them. Caregiver burden has been identified as an increasing issue 
(Lilly, Robinson, 2012; Almberg, Grafstrom, and Winblad, 1997; Brodaty, Green \& Koschera, 2003) with fewer long term services being available (Armstrong \& Kitts, 2001) and a body of caregivers who are themselves often growing old. The greater presence of social workers in the community would help support caregivers in their role, advocating for support by formal health systems, as well as respite systems for caregivers themselves, and ultimately to begin the discussions for the transition of those few older people who need residential care.

What then are the specialised contributions that social workers can make? Facilitation skills, supporting family decision making, coordination and communication are core. Social workers also possess the skills to address elder abuse/ neglect and issues of grief and loss. Some scenarios are provided below to illustrate the types of problems and related decision-making faced by older adults and the potential for social workers in primary care to assist in the resolution of difficult and distressing problems faced by older adults and their caregivers.

\section{Facilitating decision making}

Social workers have skills in working with family systems and facilitating problem-solving skills. Decision making in social work practice is a core professional task, however, the importance of this activity often goes unrecognised. The decision to move into residential care, for instance, is best made with the older person in consultation with significant others, and in a measured way. This allows the older person to explore options at a pace that is acceptable to them. Too often this decision is made following, or during, an acute admission to hospital, where decision making is compromised not only by the urgency of the need to discharge the patient from acute care, but also by the sudden frailty and change of health status of the older person coupled with caregiver anxiety.

\section{Scenario one}

Mrs Reedy is an 88-year-old widow who lives alone in a damp, non-insulated house in the inner city. She has been hospitalised three times in the last three years for a fractured femur, pneumonia and a slight heart attack. She is becoming increasingly forgetful and now refuses to spend any money on heating. She has home help, help with personal care and meals on wheels during the week. She has no family apart from a niece who lives in the next town, $80 \mathrm{kms}$ away. A referral has been made to the social worker by her neighbour to talk to her about moving into residential care. The social worker visits and spends some considerable time building a relationship with Mrs Reedy before discussing the decision to move into residential care. After consultation with Mrs Reedy she also includes the niece and the home help in the decision-making process.

Scenario one illustrates a decision-making process that is inclusive, is carried out in Mrs Reedy's home, and is done at a pace that Mrs Reedy can manage. The process of leaving her home and entering a residential care facility is facilitated by the social worker who can acknowledge the grief involved in leaving her home and possibly her neighbourhood, as well as help her to liaise with the NASC and GP to facilitate the assessment process. Placement in residential care following an acute admission to hospital does not have this luxury of time and the sudden transition often leaves the older person traumatised, as the decision is made in an environment where the older person is already very vulnerable, and generally feels powerless.

The current 'ageing in place' policy has created a greater need of continuity between the home-based system of care and acute hospital care. The longer people stay at home, 
the higher the risk of their being admitted to hospital (Richmond, 1997), therefore services between primary and secondary care need to be much more aligned than they are at present. Social work can take a lead role in advocating for better integration of services in the community and is in a unique position to facilitate integration of care between primary and secondary services.

In part, the need for integration has been recognised by District Health Boards and much work has been accomplished towards aligning strategies. For example the strategy for the care of older people from the Hawke's Bay District Health Board (HBDHB, 2011) advocates the development of multidisciplinary teams of health practitioners with advanced competence to case manage/coordinate older people in the community who are considered at 'high risk'. Among most District Health Boards there is now an understanding that if we are to meet the needs of older people in the future, many of our services need to be placed in the community and access improved.

\section{Elder abuse}

In general, elder abuse is not uniformly well recognised, reported or dealt with in our community. Elder abuse is a very complex social issue and 'occurs indiscriminately across cultures, races and socio-economic environments. An older abused adult may be marginalised, age in silence, become invisible in society, and some may lose up to 10 years of life' (Frew, 2011, p.14). It is often linked to highly stressful carer circumstances, for example multiple competing caregiver roles. Ageing at home, often with the support of stressed caregivers, can lead to situations where abuse of the older person occurs. Research reported by two New Zealand social workers adds to our understanding of the problems of elder abuse. Maher (2005) noted the need for better education and guidelines on elder abuse for those working with older adults. In 2007, the Ministry of Health published the Family Violence Intervention Guidelines: Elder Abuse and Neglect, but in a recent study by Frew (2011) it was noted that there is a lack of training in elder abuse and very low awareness of the guidelines. Professionals may sympathise with caregivers when the care relationship and responsibilities can be very stressful and demanding. Frew notes that services for abused older adults services are provided by NGOs and queries whether the issue of elder abuse might 'be taken more seriously, as is child abuse, if the Government itself provided an elder abuse service?' (Frew, 2011, p. 92). There is a clear role for social workers here in ensuring that primary care professionals can be part of a supportive team in dealing with the many fraught situations of abuse, neglect and exploitation that may trouble and harm older adults.

\section{Scenario two}

Mrs Sing is a depressed, increasingly frail 70-year-old Chinese woman who migrated to New Zealand with her son's family some years ago. Her son and his wife have not adapted well to New Zealand life, and often return to China for long periods, leaving Mrs Sing alone in the house with the their two children, aged 12 and six years. She has little English, is afraid of engaging with her neighbours, and is often taunted by passing children. She is dependent on her son for money to survive, but this is sporadic and her neighbours notice that she and the children appear distressed. Mrs Sing was referred to the social worker when she arrived at her GP's office with the children in a distraught state.

In Scenario two a supportive and non-judgemental role may also need to be provided to the son and daughter-in-law in order that Mrs Sing is able to decrease her distress. A sensitive assessment is needed to assess the well-being of the children. 


\section{Grief and loss}

Social workers will inevitably find themselves working with grief and loss. Working with older people means working with those coming towards the end of their lives. It also means having contact with caregivers who are losing the role that has filled a large part of their lives. Caregivers may experience many mixed and conflicting emotions. Guilt, loneliness and depression, loss of role, and relief may all be experienced at the same time, but all too often older caregivers are given little opportunity to grieve. A focus on the practical and financial arrangements will often take precedence over the psychosocial issues, simply because the resource of time is not there or the service is provided by those without the requisite training to offer counselling or mental health support.

\section{Scenario three}

Mr Evans (82) had cared for his wife since she developed dementia. Over time he felt he gave up all his interests - golffirst, then his choir and voluntary work. After eight years, when her confusion worsened and the burden of constant care became too much he reluctantly agreed that Mrs Evans needed rest home care. $\mathrm{Mr}$ Evans is grief stricken by this separation and despite support from family and friends is unable to pick up any of his former interests. He loses confidence, becomes depressed and turns to alcohol. His family are unable to get him help with his drinking or depression. In spite of his continuing physical fitness, he too goes into a rest home, at his own request as he cannot manage alone.

Scenario three will resonate with many social work practitioners. Working with caregivers following the placement of partners or parents is a critical part in the restoration of their physical and emotional health. Expressions of grief and loss and working through them are an important role for social work, but these particular skills of social workers remain an often untapped resource and many older people remain isolated and their depression untreated (Chew-Graham, et al, 2012; Van't Veer-Tazelaar, et al, 2009) or masked by alcohol dependence (Rinfrette, 2009).

\section{Models for social work in primary care}

The examples outlined above suggest a fruitful context for the development of social work. The signs are positive for a more positive engagement in primary care. Over the previous decade there has been a major shift in the focus of health spending from secondary to primary care (Health Workforce New Zealand, 2011). The intent of this policy change is to provide better intervention earlier, so that people who present unwell are less likely to be admitted to hospital. As part of this shift, there have been sporadic efforts over the last five years to introduce social work into the primary care environment by attaching them to GP practices. As an example, Manaia Health (a primary health organisation) in Northland has been piloting a social worker in a GP practice in Whangarei since 2009. The catchment area of the GP practice concerned contains $14 \%$ of people over the age of 65 , however this group makes up $40 \%$ of the social worker's referrals. Much of the work carried out with older people centres on elder abuse, depression, caregiver support and initiating residential care discussions. This pilot has been considered a successful venture, and the establishment of another two positions for social workers in GP practices is in progress (personal communication, June 13, 2012, CEO, Manaia Health).

Another model that is gaining traction within primary care is the Integrated Family Health Centre (IFHC) which some regions are adopting as a response to the 'Better, 
sooner, more convenient' policy of the current Government. The intent of the IFHC is to provide more streamlined care to its patients - recognising that with an increasingly ageing population, more people will be attending GP practices with chronic conditions that will need a multi-disciplinary team approach. An example of this is the IFHC envisioned by Midlands Health (2011). The concept of the multi-disciplinary team, however, appears to concentrates on medical and nursing staff with the important addition of pharmacists, who in the past have not been well-coordinated with their medical counterparts. Other members of the team are referred to as 'allied health' but their value to the team has not been well articulated.

However, neither model explores how social workers' expertise can be translated into best practice. Future models of care almost inevitably will involve multi/interdisciplinary teams, particularly as health care delivery attempts to be more cost effective, but much of the description of the current plans, while involving 'allied health', does not consider how the multi-disciplinary team might be best employed. Too often, referrals to social workers are considered in isolation from other team members. Social work intervention may best be considered alongside other health professionals, and while there is a team, working collaboratively with each other needs further examination. One model that has been used with success is the Geriatric Resources for Assessment and Care of Elders (GRACE) model of primary care, which was developed in Colorado to improve the quality of care for low-income older people. This intervention provided for an in-home assessment and care management by a nurse practitioner and a social worker working alongside each other (Counsell et al, 2007). This model needs further researching for its potential for New Zealand.

Space does not permit us to fully develop a new model here, and clearly further research is required. We do, however, support an ecological systems approach, where the older adult is placed at the centre of care systems, as shown in Figure one. O'Donoghue and Maidment (2009) describe an ecological model as being attractive to social work as it 'utilizes a mutual assessment process' involving social workers and service users with the aim to:

Figure one. An ecological systems approach.

\section{Older adult}

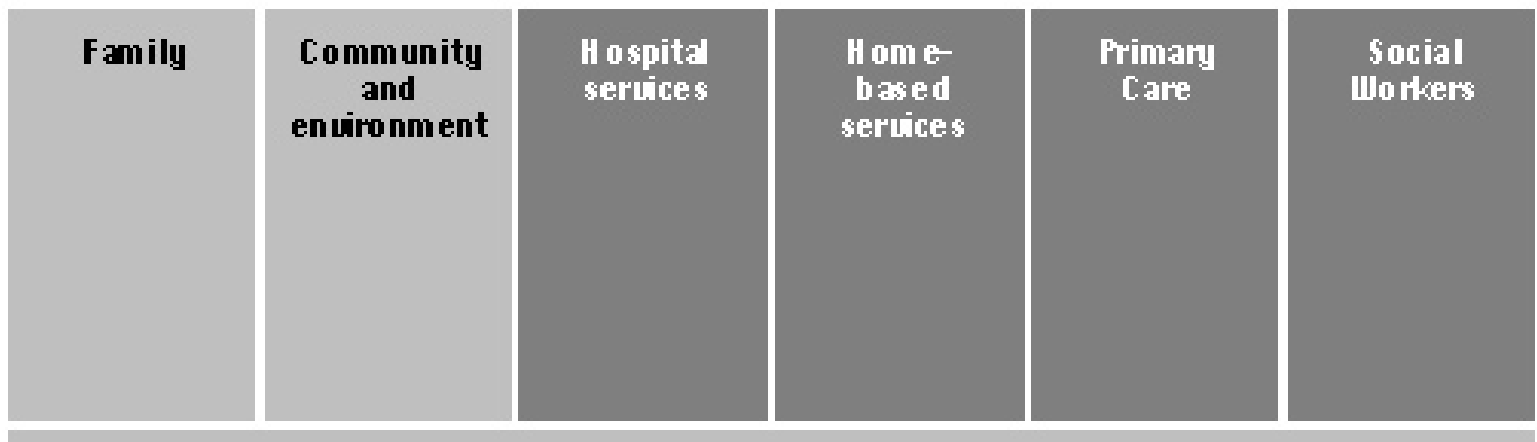


... improve the client's ability to manage life-stresses: influence the responsiveness of the social and physical environment... [and] improve the quality of person and environment interactions and relationships (p.35).

As noted by Pack (2008), a holistic health approach recognises the complex interaction of 'environmental, cultural, emotional, psychological and spiritual factors' vital for consideration if people 'are to recover from or at times live with on-going health challenges' (p.26). Such an approach can also highlight the wider social inequalities and disparities that impact on the health of groups. Older adults grow old in poor environments; the poverty and unequal opportunities they have lived with follow them into old age.

In this approach, social workers are much more able to offer a service that is both timely and accessible to the older person. Social workers in primary health are able to make home visits, unlike their hospital counterparts, and more importantly are able to provide more between primary and secondary services, as well as residential care, an area where social work is not offered at all. This ability to move across health boundaries can provide the older person and their family with a much more integrated service.

\section{Conclusions}

As a profession, social work needs to be much more articulate about our contribution, based on research and development of clear models of service. Our skills in working with families, grief work, care coordination and community networking are very well suited to intervention at the primary care level. Although the profession has significant status in relation to the protection of young people in our society, it continues to struggle for the same recognition when working with our older population. This is visible in the allocation of resources to child abuse and neglect and the much less support of services addressing elder abuse (Frew, 2011). And yet we utilise knowledge and skills in working with families and our elders which are underpinned by an evidence-based body of social work theory. Recent social work research suggests that social workers have a strong set of principles to support decisions about providing services where needed most. Giles, Gould, Hart and Swancott (2007) report the development of a set of clinical priorities for health social workers. These priorities are 1 ) addressing safety and risk issues; 2) providing social and psychological support, and 3) ensuring equitable access to the resources required to meet basic human needs (Giles et al, 2007, p.159). In this paper we have argued that there are compelling reasons that support the provision of more social work support (including psychosocial interventions, advocacy and risk assessment) to older adults in their homes and residences. An important challenge for health social work in the 21st century therefore is to establish a presence in the primary care community - a place where many more of our skills will be well utilised. It is thus time for research to be undertaken in New Zealand to explore the potential for and likelihood of acceptance by all stakeholders of a social work service provided at the primary care interface with individuals, families and communities in New Zealand.

\section{References}

Age Concern. (2006). Promoting mental health and well-being in later life: A first report from the UK inquiry into mental health and well-being in later life. London: Age Concern/Mental Health Foundation.

Aldrich, R. (2010). The ageing demographic transition: The impact on elderly and social workers. Aotearoa New Zealand Social Work Review, 22(2), 4-12. 
Almberg, B., Grafstrom, M., \& Winblad, B. (1997). Caring for a demented elderly person - burden and burnout among caregiving relatives. Journal of Advanced Nursing, 25 pp.109-116.

Armstrong, P. \& Kitts, O. (2001). One hundred years of caregiving. Law Commission of Canada. Retrieved on 13/04/12 at http: / / www.cewh-s \cesf.ca/PDF/health_reform/ care-giving-100yrs.pdf.

Auslander, G. (2001). Social work in health care: What have we achieved? Journal of Social Work 1(2), 201-222.

Barnes, D., \& Hugman, R. (2002). Portrait of social work. Journal of Interprofessional Care, 16(3), 277-288.

Beddoe, L. (2011). Health social work: Professional identity and knowledge. Qualitative Social Work. DOI:10.1177 / 1473325011415455.

Beddoe, L., \& Deeney, C. (2012). Discovering health social work in New Zealand in its published work: Implications for the profession. Aotearoa New Zealand Social Work, 24(1), 41-55.

Berkman, B., Gardner, D., Zodikoff, B., \& Harootyan, L. (2005). Social work health care with older adults: Future challenges. Families and Society, 86, 329-337.

Booth, M., Miller, E., \& Mov, V. (2007). Experts' view on long-term care in New Zealand. The New Zealand Medical Journal, 121(1286, 38-52.

Botting, C. H., \& Chetwynd, J. (1989). The influence of a social worker on the general practitioner management of psychosocial problems. New Zealand Family Physician, 16(1), 3-6.

Briggs, L., \& Colhoun, H. (1990). Evaluating service effectiveness in a health setting. Social Work Review, 3(1 \& 2), 14-19.

Brodaty, H., Green, A., \& Koschera, A. (2003). Meta-analysis of psychosocial interventions for caregivers of people with dementia. Journal of the American Geriatrics Society, 51(5), 657-664.

Bywaters, P. (1986). Social work and the medical profession: Arguments against unconditional collaboration. British Journal of Social Work, 16(6), 661-667.

Canadian Association of Social Workers. (CASW). Enhancing interdisciplinary collaboration in primary health care initiatives. Retrieved 30/01/10 from http:/ / www.casw-acts.ca/index.html.

Canadian Association of Social Workers (CASW). (2003). Preparing for change: Social work in primary health care, November 2003. Retrieved 30/01/10 from http:/ / www.casw-acts.ca/index.html.

Chew-Graham, C., Kovandzić, M., Gask, L., Burroughs, H., Clarke, P., Sanderson, H., \& Dowrick, C. (2012). Why may older people with depression not present to primary care? Messages from secondary analysis of qualitative data. Health \& Social Care in the Community, 20(1), 52-60.

Cooper, A. (2010). What future? Organisational form, relationship-based social work practice and the changing world order. In G. Ruch, D. Turney \& A. Ward (Eds.), Relationship-based social work (pp. 229-243). London: Jessica Kingsley.

Counsell, S., Callahan, C., Clark, D., Wanzhu, T., Buttar, A., Stump, T., Ricketts, G. (2007). Geriatric care management for low-income seniors: A randomised controlled trial. Journal of the American Medical Association, 298(22),2623-33.

Craig, T. (1980). Social work in primary health care: A New Zealand study. Christchurch: Health Planning and Research Unit.

Davey J. (2006). 'Ageing in place': the views of older homeowners on maintenance, renovation and adaptation. Social Policy Journal of New Zealand, 27, 128-145.

Dwyer, M., Gray, A. \& Renwick. M. (2000). Factors affecting the ability of older people to live independently. Wellington: Ministry of Social Policy.

Foote, C., \& Stanners, C. (2002). Integrating care for older people. New care for old - a systems approach. London: Jessica Kingsley.

Foster, S. (2003). An analysis of the skills and knowledge base for needs assessment and service coordination. Unpublished Masters of Social Work thesis. Massey University.

Frew, C. (2011). How do primary healthcare practitioners respond to elder abuse? Unpublished Master of Health Sciences thesis. University of Auckland.

Giles, R., Gould, S., Hart, C. \& Swancott, J. (2007). Clinical priorities: Strengthening social work practice in health. Australian Social Work, 60(2), 147-165.

Hawkes Bay District Health Board (2011). Improving health services for older people in Hawke's Bay. Retrieved 05-10-12 http: / / workforceinnovation.hiirc.org.nz/page/32348/improving-health-services-for-older-people.

Health Workforce New Zealand. (2011). Health Workforce New Zealand: Annual Plan (2011). Wellington: Ministry of Health.

Irish Association of Social Workers. (2010). Primary care social work: Definition and role. Retrieved 11-12-2011 from http:/ / www.iasw.ie/index.php/ special-interest-groups/ sig-social-workers-in-primary-care

Keefe, B., Geron, S.M., \& Enguidanos, S. (2009). Integrating social workers into primary care: Physician and nurse perceptions of roles, benefits, and challenges. Social Work in Health Care, 48, 579-596.

Lilly, M.B., Robinson, C.A. Holtzman, S., \& Bottorff, J.L. (2012). Can we move beyond burden and burnout to support the health and wellness of family caregivers to persons with dementia? Evidence from British Columbia, Canada. Health and Social Care in the Community, 20(1), 103-112.

Maher, P. (2005). A study of social work practitioners and their needs when intervening in cases of elder abuse and neglect. Unpublished Master of Social Work thesis. University of Canterbury.

Midlands Health Network. (2011). Integrated family health centres.Waikato: Waikato District Health Board.

Ministry of Health. (2002). Health of older people strategy. Wellington: Ministry of Health. 
Ministry of Health (2007a). Family violence intervention guidelines: Elder abuse and neglect. Wellington: Ministry of Health.

Ministry of Health (2007). Primary health care strategy: Key directions for the information environment. Wellington: Ministry of Health.

Ministry of Health. (2011). Better, sooner, more convenient health care in the community. Wellington: Ministry of Health.

Murray, C. J. L., \& Lopez, A. D. (Eds). (1996). The global burden of disease: A comprehensive assessment of mortality and disability from diseases, injuries and risk factors in 1990 and projected to 2020. Boston: Harvard University Press.

Nuthall, J. J. (1989). Players or spectators in the new public health? Social Work Review, 2(1), 6-10.

O'Donoghue, K., \& Maidment, J. (2009). The ecological systems metaphor in Australasia. In M. Nash, R. Munford \& K. O'Donoghue (Eds.), Social work theories in action (pp. 32-49). London: Jessica Kingsley.

Opie, A. (1995). Beyond good intentions: Support work with older people. Wellington, N.Z.: Institute of Policy Studies, Victoria University of Wellington.

Opie, A., \& Munford, R. (1995). Exploring effective strategies for enhancing social workers' contributions in multidisciplinary teams. Social Work Review, 7(4), 3-8.

Pack, M. (2008). An innovation in primary mental health services: The MidValley Well-being Service. Social Work Review, 20(3), 25-33.

Phillips, R. (1999). Value-added social work: Value-added service delivery enhances hospital social work practice. Social Work Review, 11(2), 18-20.

Richmond, D. (1997). Home is where the heart is: The Northern Health case management study: a joint project of North Health and Waitemata Health. Auckland: North Health.

Rinfrette, E.S. (2009). Treatment of anxiety, depression, and alcohol disorders in the elderly: Social work collaboration in primary care. Journal of Evidence-Based Social Work, 679-91.

Ruch, G., Turney, D., \& Ward, A. (Eds.). (2010). Relationship-based social work. London: Jessica Kingsley.

Schofield, V. (2001). Health social work. In M. Connolly (Ed.), New Zealand social work: Contexts and practice (pp. 146-156). Auckland: Oxford University Press.

Smith, J., \& Cumming, J. (2009). Where next for Primary Health Care Organisations in New Zealand? Victoria University of Wellington, School of Government Health Services Research Centre. Retrieved 02 / 12/ 2011 from http:/ / www. moh.govt.nz/moh.nsf/indexmh/ where-next-primary-health-care-nz.

Van't Veer-Tazelaar P.J., van Marwijk H., Jansen, A., Rijmen, F., Kostense, P., van Oppen, P., A Beekman, A. (2009). Depression in old age (75+), the PIKO study. Journal of Affective Disorders, 106(3), 295-299.

Weld, N. (2009). Resuscitating health social work. Aotearoa New Zealand Social Work Review, 21/22(4/1), 25-33.

World Health Organisation. (1978). Retrieved 02/12/2011 from http:/ / www.who.int/publications/almaata_declaration_en.pdf. 